\title{
An Analysis of the Teachers' Climate Change Awareness
}

\author{
By Burckin Dal* \\ Nilay Ozturk ${ }^{\dagger}$ \\ Umut Alpert \\ Duygu Sonmez \\ Aytekin Cokelez.
}

This paper reports a study conducted to investigate social studies and science teachers' awareness on climate change and how the professional development workshop "Awareness and Adaptation to Climate Change" affects teachers' awareness level. For this purpose, a total of 101 teachers from 8 different cities and 4 geographical locations participated in the workshop and took part in the study. For data collection purposes, the Awareness to Climate Change Questionnaire (ACCQ) was used. The analysis revealed no statistical difference among participating teachers' awareness level based on pre-test scores. However, further analysis indicates an increase in awareness on climate change among participating teachers upon completion of the professional development workshops.

Keywords: awareness, climate change, teacher

\section{Introduction}

Climate change has become one of the most serious environmental problems faced in the $21^{\text {st }}$ century threatening public health and food security (Parry, Rosenzweig, Iglesias, \& Fischer, 1999). Nonetheless, very few people are aware of the negative effects of climate change. Most of the research on climate change focuses on the public understanding of climate change for the purpose of identifying human perception on the topic. Many scholars have analyzed the issue of climate change in recognition of public perception (Sampei \& Aoyagi-Usui, 2009). Scientific and policy discussions of climate change could lie in roots of improved understanding of public perception. Bord, Fisher and O'Connor stated that "scientists need to know how the public is likely to respond to climate impacts or initiatives since those responses can qualify or amplify these impacts" (1998, p. 75). Thus and so, a public awareness is crucial to firstly understand the negative effects of human actions,

\footnotetext{
*Associate Professor, Istanbul Technical University, Turkey.

${ }^{\dagger}$ Research Assistant, Middle East Technical University, Turkey.

${ }^{\ddagger}$ Research Assistant, Atilim University, Turkey.

${ }^{+}$Assistant Professor, Hacettepe University, Turkey.

-Associate Professor, Istanbul Technical University, Turkey.
} 
and secondly to take action for the prevention and adaptation to climate change. Consequently, climate change is a problem demanding a great deal of attention by scientists, policymakers, and the public as well; and for this reason, recently there has been a great interest in public understanding of climate change and in educating pupils, the future citizens, so as to enable them to successfully cope with this threat (Papadimitriou, 2004).

However the term "climate change" is confused with the term "global warming" (Schuldt, Konrath, \& Schwarz, 2011). It is assumed that mass media and teachers have a big role in the confusion of this concept. Many scholarly articles focus on the mass media coverage of climate change studying the relation (Segev \& Baram-Tsabari, 2010). Moreover, there are studies on how the media affects public understanding of climate change. Even though there are studies about teachers and climate change issues, there are not many media studies (Savaşçı-Açıkalın \& Açıkalın, 2011). This is the situation especially in Turkey. Teachers are the second population influenced, especially when students are in question. Teachers' awareness of climate change might provide teachers with more knowledge about the subject. Manteaw (2012) describes awareness as an action to global issues and sustainable development and, therefore, connects it to education. To achieve that, importance of education, awareness and training is highlighted in changing behavior in the study by Leal, Pace, and Manolas (2008). According to Pruneau et al. (2001), climate change is an issue which affects all parts of life and requires education to be considered as a whole without the boundaries of disciplines. For that, studies emphasize the importance of teachers giving high priority on climate change to assure a proper understanding on the content among their students. However, those studies also state that teachers' own knowledge on the content is inadequate to teach it (Fortner, 2001). Additionally, Fortner (2001, p. 18) stated that students and some teachers seem unable to recognize environmental issues.

In this study, teachers are examined as a bridge between the education and the students - citizens of future. There is a positive correlation between teachers' awareness of climate change and their students. The more teachers' awareness of climate change is, the more their students' is. In Turkey, science and social science education curricula includes content closely related with the climate change science issues. That is why teachers from these two content areas were chosen to take part in this study. Climate change awareness of those teachers from different cities of Turkey is surveyed in this research.

\section{Background}

Some of these studies focus on common sense in public about climate change (Schuldt, Konrath, \& Schwarz, 2011; Whitmarsh, 2009). Moreover, for studies that surveyed the causes of climate change (Crowley, 2000; Öztürk, 2002; Sağlam, Düzgüneş, \& Balık, 2008), the results of these studies have revealed that many people hold misconceptions about the climate change 
science and are especially confused about the nature, reasons and results of it. Sharma (2012) identifies education as a social solution of developing and understanding the relations between nature and modern societies and developing sustainable actions as responsible citizens.

There are several qualitative and quantitative surveys about mass media coverage of climate change issues. Some of them are about effects of mass media coverage on public understanding climate change (Antilla, 2008; Gavin, 2009; Lyytimäki \& Tapio, 2009). Those studies concluded that the mass media affects public comprehension of climate change. However, a special interest should be paid to teachers and prospective teachers perceptions on the topic due to their role in public understanding. There is a relationship between student learning outcomes and how they are taught which has been a topic of various studies. Based on the outcome of these studies, it is indicated that there is a direct and positive relationship between teachers' effectiveness and students' learning outcomes (Sanders \& Rivers, 1996; Westerlund, 2002). Therefore, there has been a special interest in teachers' professional development. This study also takes teachers' role in public understanding, especially on students, into account.

Papadimitriou (2004) studied "student teachers perceptions on aspects of climate change as well as on greenhouse effect and ozone layer depletion" and as the author states, teachers were found to be unaware of the proper actions for the climate change. With the similar findings, Fortner (2001) and Dove (1996) manifested that teachers do not have an adequate knowledge to develop awareness and spread it to others. A similar outcome was also stated in a study conducted in Turkey by Çelikler and Aksan (2011), which showed that teachers' awareness on environmental issues was inadequate. Each of the studies above indicates that teachers have problems with awareness of the Earth system relationships and the impact of human activities on Earth systems. Many researchers argue on the importance of professional development opportunities for teachers, especially on subject matter content knowledge since research addresses lack of content knowledge of teachers as an issue (Garet, Porter, \& Desimone, 2001; Kennedy, 1998).

The research reported here focuses on Turkish teachers' understanding of climate change with an aim to provide information that can be useful for the Turkish teachers in planning and organization. As part of the project, "The Impacts of Climate Change and Raising Awareness about Adapting the Climate Change", study intends to explore teachers' understanding about climate change. However, the impetus of this study is based on the need for valid and reliable instruments to measure knowledge of and attitudes toward climate change so that effective curriculum and instructional implementation can be measured.

The aim of the project "The Impacts of Climate Change and Raising Awareness about Adapting the Climate Change" is to develop national and regional capacity to manage climate change risks at urban, rural and coastal areas of Turkey and to create awareness on impacts and adaptation to the 
climate change by providing teachers with more information about the issue. The project includes in-service teacher training on Climate Change Adaptation and Awareness through workshops. While the project aims to develop an awareness and understanding on climate change and to raise awareness in creating innovative ideas on how to be environmentally friendly at an individual and social perspective, the purpose of this study is adaptation of an instrument that can be used to investigate individuals understanding and experiences about climate change and investigate teachers' perceptions on the matter.

\section{Professional Development Program - "Awareness and Adaptation to Climate Change"}

The professional development program titled "Awareness and Adaptation to Climate Change" was designed as a three-day in-service workshop focusing on global climate change. The selected teachers for the workshops were asked to be present on campus one day prior, and introductory activities were conducted to familiarize teachers with the workshop programs as well as faculty members and facilities.

Each day of the workshop was organized around a special theme. The emphasis of the first day of the program was given to ecology, environmental problems that we face mostly in the last century, especially global warming and sustainable development. The theme of the second day was climate change, its impacts and consequences for us and the ways to be followed for adaptation and mitigation. Finally, on the third day the focus was on energy including the subtopics of efficient ways of energy consumption and sustainable energy resources in the world. The workshops were structured around instruction, discussions, hands on activities and field trips. Morning sessions of each day consisted of instructions and discussions directed by academic scholars who are experts on the content. During these sessions, teachers were able to share their ideas and brainstorm on the selected theme and discuss environmental issues.

The main aim of the afternoon sessions was to provide teachers with firsthand experience with climate change activities, which they can later implement in their own classrooms. The activities were designed on four themes (a) the effects of waste on climate change and the importance of waste reduction and management; (b) biodiversity and its importance; (c) scavenger hunt activity about climate change; (d) energy-saving. In addition to the teaching activities, field trips were also included in the workshop program such as the trip to a waste management center, named Izmit Waste and Residue Treatment, Incineration and Recycling Co. Inc. Throughout the field trip, teachers were given information by the experts of the center on how the waste of the whole city is treated and recycled in the process. Benefits of being part of such an experience were twofold for the teachers; first of all, they were able to experience a waste management facility and to learn about how different wastes need to be treated and disposed of for the sake of the environment and 
the importance of waste management. And secondly, by taking part in a field trip they were able to experience the educational value of field trips as part of a learning process.

Another activity that took place during the workshops was the science show on the carbon cycle. This show integrates science into theater and was a good opportunity to show teachers the value of informal learning environments for effective teaching and learning. The Science show was very attractive for teachers, which also had the potential to encourage them for such cooperation with local groups where they can present their own students with a learning environment that is fun and motivating. The workshop also included a session on developing projects. The purpose of this session was to provide teachers with the necessary tools that they can develop their own projects with their students about environmental problems, especially climate change, and how they can prepare action plans. Each evening of the workshops were dedicated to either a movie or a documentary on global climate change and discussions where teachers got the opportunity to closely interact with other teachers as well as the instructors.

\section{Purpose of the Research}

With the consideration of the importance of teachers' role on students' understanding and achievement, this study focuses on teachers' perception of climate change. For this purpose, selected teachers were invited to take part in a professional development opportunity focusing on climate change and its' impact on the environment. The study was conducted with the following research questions in mind (a) How teachers perceive climate change? (b) Is there a difference between teachers' perceptions on the issue depending on the geographical locations they are selected from? (c) How effective is the professional development program?

Overall, this study's, and thus this project's, aim is to provide teachers with effective professional development programs focusing on climate change and to increase the awareness on issues and adaptation behavior.

\section{Methodology}

\section{Sample}

The strategy for the selection of participants was convenient for the sampling. As displayed in Table 1, the present study involved a total of 101 teachers from the four different regions, (Marmara, Aegean, Black Sea and Central Anatolia) and 8 different cities, (Edirne, Bursa, Konya, Kayseri, İzmir, Muğla, Trabzon, Samsun) of Turkey nearly in equal numbers. These geographical regions and cities were selected as pilots. Teachers who teach science education and social sciences education were selected for this study 
from two different content areas. The reason for choosing teachers from these two disciplines was the education programs of these two content areas. In middle school grade levels, climate change is taught as a part of science and social sciences curriculum.

Among all the participants, more than half of the participants were male and the majority of the teachers had medium or high experience based on their years in teaching. In addition, the majority of the teachers held an undergraduate degree.

In addition to demographics presented in Table 1, teachers were asked whether they attended any training before or worked in a project on climate change or global warming. Unfortunately, more than half of the teachers responded that they never attended any training before nor worked in a project. Hence, for most of the teachers, this training was the first they attended in their professional career.

Table 1. Socio-Demographic Characteristics of the Sample

\begin{tabular}{|c|c|c|}
\hline & $f$ & $\%$ \\
\hline \multicolumn{3}{|l|}{ Gender } \\
\hline Female & 39 & 38.6 \\
\hline Male & 62 & 61.4 \\
\hline \multicolumn{3}{|l|}{ City } \\
\hline Edirne-Bursa & 28 & 27.7 \\
\hline Konya-Kayseri & 24 & 23.8 \\
\hline İzmir-Muğla & 26 & 25.7 \\
\hline Trabzon-Samsun & 23 & 22.8 \\
\hline \multicolumn{3}{|l|}{ Teaching area } \\
\hline Science education & 54 & 53.5 \\
\hline Social sciences & 47 & 46.5 \\
\hline \multicolumn{3}{|l|}{ Experience } \\
\hline $0-5$ & 12 & 11.9 \\
\hline $6-15$ & 48 & 47.5 \\
\hline $16-35$ & 40 & 39.6 \\
\hline \multicolumn{3}{|l|}{ Education level } \\
\hline Two-year college & 1 & 1.0 \\
\hline$B S$ & 92 & 91.1 \\
\hline$M S$ & 4 & 4.0 \\
\hline \multicolumn{3}{|l|}{ Attended any training? } \\
\hline Yes & 34 & 33.7 \\
\hline $\mathrm{No}$ & 64 & 63.4 \\
\hline \multicolumn{3}{|l|}{ Worked in a project? } \\
\hline Yes & 27 & 26.7 \\
\hline No & 69 & 68.3 \\
\hline
\end{tabular}

\section{Data-Collection Instrument}

The instrument used for the purpose of data collection was titled "Awareness to Climate Change Questionnaire" (ACCQ), which was developed by Halady and Rao (2010). The questionnaire includes Likert type items 
where, 1: I'm not aware, 2: I'm somewhat aware, 3: I'm aware, and 4: I'm strongly aware. The Questionnaire measures the awareness level on different aspects of climate change and aims to determine any statistical significance between awareness and behavioral change. The final ACCQ was found to accurately measure whether awareness to the climate change phenomenon leads to significant behavioral change, alleviating the potential and existing threats of the climate change phenomenon (Halady \& Rao, 2010).

The ACCQ was comprised of four sections (a) reasons and impacts of climate change; (b) awareness of individual initiative; (c) awareness of what industry can do; (d) propensity for behavioral change. Table 2 presents the sections of the questionnaire. The reported factors under each section were tested by a confirmatory factor analysis for validation among adult participants in Turkish context in a prior adaptation study. During the adaptation study, in order to ensure factorial validity of the scale model, fit indices were examined deeply. In this sense, CMIN/df values were between 2 and 5, Comparative Fit Indexes (CFI) were close to 1 , the root mean square error of approximation (RMSEA) values were less than 0.05 , standardized root mean square residuals (SRMR) were found less than 0.10 for all sections of the scale. CFA results showed that this questionnaire was found to be acceptable regarding to factorial validity. The alpha coefficient of the instrument was calculated as 0.97 , which also corresponds with the original study and indicates that the instrument is valid.

Table 2. The Four Sections of the ACCQ

\begin{tabular}{|c|c|}
\hline Section of the Questionnaire & Factors reported \\
\hline $\begin{array}{l}\text { Reasons and impacts of } \\
\text { climate change }\end{array}$ & $\begin{array}{l}\text { Impact on health ( } 9 \text { items) } \\
\text { Water level ( } 5 \text { items) } \\
\text { Reasons causing climate change ( } 3 \text { items) }\end{array}$ \\
\hline $\begin{array}{l}\text { Awareness of individual } \\
\text { initiative }\end{array}$ & $\begin{array}{l}\text { Energy conservation (13 items) } \\
\text { Reduce GHG in car use (5 items) } \\
\text { Active environmentalist (5 items) } \\
\text { Climate change friendly lighting ( } 2 \text { items) }\end{array}$ \\
\hline $\begin{array}{l}\text { Awareness of what industry } \\
\text { can do }\end{array}$ & $\begin{array}{l}\text { Conservation of energy ( } 8 \text { items) } \\
\text { Climate change friendly material ( } 6 \text { items) } \\
\text { Systems ( } 1 \text { items) }\end{array}$ \\
\hline $\begin{array}{l}\text { Propensity for behavioral } \\
\text { change }\end{array}$ & $\begin{array}{l}\text { Behavioral change to climate change ( } 6 \text { items) } \\
\text { Lead climate change campaign ( } 2 \text { items) }\end{array}$ \\
\hline
\end{tabular}

\section{Data-Collection Procedure and Analyses}

The pre- and post-test approach was adapted for the data collection purposes. The data collection was completed on site by the researchers. The participation to the study was voluntary and teachers had the right to withdraw from the study at any time if they chose to do so.

The study aimed to identify if there is any change in climate change 
awareness among teachers after attending the in-service training. For this purpose, initially an analysis of a variance test used to examine whether there were any differences among participants originating from different geographical regions of Turkey based on pre-test scores. Further analysis was conducted through paired sample t-test analysis.

\section{Results}

The framework for the analysis was adapted from the original study conducted by Halady and Rao (2010) with the consideration of research questions.

\section{Science and Social Science Teachers' Climate Change Awareness}

ANOVA. Analysis of variance was conducted to examine whether there were any differences in groups' climate change awareness before the in-service training. For this purpose, pre-test scores were used which were collected during day of the workshops. As displayed in Table 3, ANOVA results revealed that there were no statistical differences among the four groups in terms of climate change awareness before the training $\mathrm{F}(3,97)=0.525, \mathrm{p}=$ 0.66 . Therefore, for further analysis, all of the participants were considered as the unit of analysis as a whole rather than taking the geographical or city origin into an account.

Table 3. ANOVA Results

\begin{tabular}{|l|c|c|c|}
\hline & df & F & p-value \\
\hline Between groups & 3 & 0.525 & 0.666 \\
\hline
\end{tabular}

T-test analyses. A Paired sample t-test analysis was conducted to investigate the impact of the "Awareness and Adaptation to Climate Change" workshops and whether there was a difference between teachers' in pre and post-test awareness scores (Table 4).

Table 4. Paired Sample T-Test Statistics

\begin{tabular}{|l|c|c|c|c|}
\hline & t & df & p-value & Eta-squared \\
\hline Pair ACC1-ACC2 & $-6,297$ & 85 & $0.000^{*}$ & 0.31 \\
\hline
\end{tabular}

As seen in Table 4, there was a statistically significant difference between the mean scores of science and social science teachers' overall awareness to climate change before and after the in-service training. The eta-squared statistics 0.31 indicated a moderate effect size (Cohen, 1988).

Having established that there was a statistically significant difference, the mean values were examined to find which set of scores were higher (ACC1 or ACC2). The pre-test mean scores of overall climate change awareness was calculated 3.31 meaning that the teachers reported that they were aware of the topic. The post-test mean score was calculated as 3.84 indicating a stronger 
awareness presented in Table 5. Based on the calculated mean values and t-test analysis, a statistically significant increase was found between pre- and posttest scores of the participating teachers.

Table 5. Comparison of Teachers' Climate Change Awareness

\begin{tabular}{|l|c|c|c|}
\hline & N & M & SD \\
\hline Pair ACC1 & 86 & 3.31 & 0.40 \\
\hline ACC2 & 86 & 3.84 & 0.70 \\
\hline
\end{tabular}

In detail, Table 6 displays the significance values concerning the four subdimensions of the "Awareness to Climate Change Questionnaire" (a) reasons and impacts of climate change; (b) awareness of individual initiative; (c) awareness of what industry can do; (d) tendency for behavioral change.

Table 6. T-test Results Considering each Sub-Dimension

\begin{tabular}{|l|c|c|c|}
\hline Sub-dimension & Pre-test mean & Post-test mean & p-value \\
\hline $\begin{array}{l}\text { Reasons and impacts of climate } \\
\text { change }\end{array}$ & 3.18 & 3.67 & $0.000^{*}$ \\
\hline Awareness of individual initiative & 3.40 & 3.83 & $0.000^{*}$ \\
\hline Awareness of what industry can do & 3.24 & 3.80 & $0.000^{*}$ \\
\hline Tendency for behavioral change & 3.30 & 3.73 & $0.000^{*}$ \\
\hline
\end{tabular}

As seen from the results, it can be determined from the pre-test scores that teachers share a reasonably acceptable level of awareness for subscales of reasons and impacts of climate change, awareness of individual initiative, and awareness of what industry can do, and tendency for behavioral change. However, an increase in awareness was identified when post-test scores were analyzed in comparison to pre-test scores indicating a stronger awareness on all sub-dimensions, which can be attributed to the in-service workshops.

\section{Discussion}

Teachers' understanding and awareness on environmental issues, such as climate change, are vital for the development of an understanding on a larger scale, especially when younger generations are in question. Therefore, educational opportunities focusing on teachers' knowledge, understanding and awareness have value, and their impact should be studied for the development of better learning opportunities. To this end, this study was focusing on teachers' awareness on climate change and was investigating the impact of a professional development workshop called, "Awareness and Adaptation to Climate Change".

Social studies and science teachers from four different locations took part in the study, and based on the pre-test scores, no statistical difference of awareness was found among participating teachers' on climate change. This outcome may be attributed to the fact that teachers come from different cities or 
geographical locations regardless the city they are working in. Pre-test results also revealed that although climate change is related to the field of teaching, social studies and science in-service teachers are unaware of the climate change issue. For each sub dimension of reasons and impacts of climate change, awareness of individual initiative, awareness of what industry can do, and tendency for behavioral change, the mean values were ranged between 3.18 and 3.40. That shows teachers have quite a low level of awareness regarding the climate change. Although there is a very limited number of studies on in-service teachers' climate change awareness, existing research studies have also revealed similar results. For instance, Papadimitriou (2004) asserted that prospective teachers, enter the university holding many misconceptions and misunderstandings concerning the climate change. After starting the field as a teacher, these misconceptions may tend to become persistent and very resistant to change. Similarly, in another study focusing on Vietnamese primary teachers' awareness on environmental problems and their capacities to meet the requirements of environmental education revealed that both the awareness and capacities of Vietnamese primary school teachers on environmental education were insufficient (Than, 2001).

The second part of the analysis investigated the impact of the workshop on teachers' awareness. Both the overall questionnaire and the subscales analysis revealed that teachers have awareness on the topic. Since both social studies and science curriculum include content on climate change, it is expected to have teachers to have at least a basic understanding and awareness on the topic. However, since this study does not focus on teachers' knowledge on the content it is not possible to predict on the knowledge level of the participants on climate change. When post-test scores were analyzed, an increased level of awareness was found. Although the increase in teachers' awareness of global climate change is not large, this outcome shows a positive impact of the workshop on participating teachers' awareness on climate change.

\section{Implications for Teacher Professional Development and Conclusions}

Ever since climate change had been accepted as one of the most important issues of the new century, individuals' behavior, perceptions, their knowledge and awareness in relation to climate change mitigation and adaptation were started becoming the focus of research studies (Whitmarsh, 2009). To raise new generations with an awareness and perception of the climate change issue has been one of the aims of science education. To this end, first of all, teachers' behaviors, perceptions, and awareness are vital to be increased. Besides, the majority of teachers are unfamiliar in how to educate their students about issues such as climate change since they heavily based their teaching on traditional didactic strategies (Papadimitriou, 2004). Therefore, like in the present study, the number of in-service teacher training workshops aiming to increase both teachers' awareness on climate change and to develop their teaching strategies and skills regarding climate change should be increased.

Apart from the efforts of in-service teachers, in order to raise teachers with 
an awareness of environmental problems such as climate change and capabilities to teach these topics, it may be better to integrate climate change education into teacher education programs for both social science and science education teachers. For instance, it may be helpful to design courses about climate change awareness. Besides, pedagogical courses focusing specifically on the instructional skills for the teaching of environmental problems such as climate change may provide teachers with the competencies to teach climate change in science classrooms.

Workshops such as "Awareness and Adaptation to Climate Change", which integrates instruction and teaching activities, creates opportunities for teachers who are already in the workforce to keep up with the changing nature of knowledge and follow recent scientific developments. Although the study was not focusing on teachers' content knowledge, as seen from this study the professional development workshop has a positive influence on teachers' awareness. For further studies, it is recommended to focus on the content knowledge as well.

\section{References}

Antilla, L. (2008). Self-censorship and science: a geographical review of media coverage of climate tipping points. Public Understanding of Science, 19(2), 240256.

Bord, R. J., Fisher, A., \& O'Connor, R. E. (1998). Public perceptions of global warming: United States and international perspectives. Climate Research, 11, 7584.

Çelikler, D., \& Aksan, Z. (2011). Determination of pre-service elementary science teachers' knowledge level about ozone layer. Procedia-Social and Behavioral Sciences, 15, 1438-1444.

Cohen, J. W. (1988). Statistical power analysis for the behavioral sciences. Hillsdale, NJ: Lawrence Erlbaum Associates.

Crowley, T. J. (2000). Causes of climate change over the past 1000 years. Science, 14(289), 270-277.

Dove, J. (1996). Student teacher understanding of the greenhouse effect, ozone layer depletion and acid rain. Environmental Education Research, 2(1), 89-100.

Fortner, R. W. (2001). Climate change in school: Where does it fit and how ready are we? Canadian Journal of Environmental Education, 6, 18-31.

Garet, M. S., Porter, A. C., \& Desimone, L. (2001). What makes professional development effective? Results from a national sample of teachers. American Educational Research Journal, 38(4), 915-945.

Gavin, N. T. (2009). Addressing climate change: a media perspective. Environmental Politics, 18(5), 765-780.

Halady, I. R., \& Rao, P. H. (2010). Does awareness to climate change lead to behavioral change? International Journal of Climate Change Strategies and Management, 2(1), 6-22.

Kennedy, M. M. (1998). Form and substance in in-service teacher education. Research Monograph. Arlington, VA: National Science Foundation.

Leal F. W., Pace, P., \& Manolas, E. (2008). Education for Sustainable Development: 
Current discourses and practices and their relevance to Technology Education. International Journal of Technology and Design Education, 19(1), 17-34.

Lyytimäki, J., \& Tapio, P. (2009). Climate change as reported in the press of Finland: From screaming headlines to penetrating background noise. International Journal of Environmental Studies, 66(6), 723-735.

Manteaw, O. O. (2012). Education for sustainable development in Africa: The search for pedagogical logic. International Journal of Education Development, 32, 376383.

Öztürk, K. (2002). Küresel iklim değişikliği ve Türkiye'ye olası etkileri. [Global climate change and its potential impact on Turkey]. G. Ü. Gazi Eğitim Fakültesi Dergisi, 22, 47-65.

Papadimitriou, V. (2004). Prospective primary teachers' understanding of climate change, greenhouse effect, and ozone layer depletion. Journal of Science Education and Technology, 13(2), 299-307.

Parry, M., Rosenzweig, C., Iglesias, A., \& Fischer, G. (1999). Climate change and world food security: a new assessment. Global Environmental Change, 9, 51-67.

Pruneau, D., Liboiron, L., Vrain, E., Gravel, H., Bourque, W., \& Langis, J. (2001). People's ideas about climate change: A source of inspiration for the creation of educational programs. Canadian Journal of Environmental Education, 6, 121138.

Sağlam, N. E., Düzgüneş, E., \& Balık, I. (2008). Global warming and climatic changes. E.U. Journal of Fisheries \& Aquatic Sciences, 25(1), 89-94.

Sampei, Y., \& Aoyagi-Usui, M. (2009). Mass-media coverage, its influence on public awareness of climate-change issues, and implications for Japan's national campaign to reduce greenhouse gas emissions. Global Environmental Change, 19, 203-212.

Sanders, W. L., \& Rivers, J. C. (1996). Cumulative and residual effects of teachers on future student academic achievement. University of Tennessee, Value-Added Research and Assessment Center.

Savaşç-Açıkalın, F., \& Açıkalın, M. (2011). Pre-service teachers' conceptions of environmental issues. Paper presented at the Conference on Educational Research, Berlin, Germany.

Schuldt, J. P., Konrath, S. H., \& Schwarz, N. (2011). "Global warming" or "climate change"? Whether the planet is warming depends on question wording. Public Opinion Quarterly, 75(1), 115-124.

Segev, E., \& Baram-Tsabari, A. (2010). Seeking science information online: Data mining Google to beter understand the roles of the media and the education system. Public Understanding of Science, 21(7), 813-829.

Sharma, A. (2012). Global climate change: What has science education got to do with it? Science \& Education, 2l(1), 33-53.

Than, N. T. (2001). Awareness of Vietnamese primary school teachers on environmental education. International Research in Geographical and Environmental Education, 10(4), 429-444.

Westerlund, J. F. (2002). Summer scientific research for teachers: the experience and its effect. Journal of Science Teacher Education, 13(1), 63-83.

Whitmarsh, L. (2009). What's in a name? Commonalities and differences in public understanding of "climate change" and "global warming". Public Understanding of Science, 18(4), 401-420.

Whitmarsh, L., \& Lorenzoni, I. (2010). Perceptions, behavior and communication of climate change. Wiley Interdisciplinary Reviews: Climate Change, 1(2), 158-161. 